\title{
Notes on emerging issues in psychoanalytic listening with the elderly
}

\begin{abstract}
The present article seeks to bring contributions about the psychoanalytic clinic with the elderly, based on our experience in the Núcleo de Atenção ao Idoso (NAI) located in the city of Rio de Janeiro. Guided by the referrals made to the psychology team, our writing aims to highlight important issues that may arise with the passing of the aging process: confrontation with hard losses; feeling of strangeness that may favor isolation; emptying relationships; complaints of forgetfulness; diagnosis of depression; among others. These issues require work of mourning, which demands time. Given this, our bet is that the entrance of psychoanalytic listening can contribute significantly to the work of elaboration, as we have learned in our practice in NAI.
\end{abstract}

Keywords: psychology, aging, elderly
Volume 9 Issue 2 - 2018

\author{
Maria Isabel Rosa da Silva Arello \\ Psychologist, Postgraduate Program of Clinical Institutional \\ Psychology, University of the State of Rio de Janeiro, Brazil \\ Correspondence: Maria Isabel Rosa da Silva Arello, \\ Postgraduate Program of Clinical Institucional Psychology, \\ University of the State of Rio de Janeiro, Brazil, \\ Email bel_arello@hotmail.com; misabel.arello@gmail.com
}

Received: March 22, 2018 | Published: April 10, 2018

\section{Introduction}

Based on our experience as a psychology resident at the Núcleo de Atenção ao Idoso linked to the State University of Rio de Janeiro and Pedro Ernesto University Hospital, we will make some notes about recurring issues in the clinic with seniors. As for the frequent reasons for referral of the multiprofessional team to the psychology service, we can highlight: the complaints of forgetfulness, especially in medical research about the presence of senile dementia syndrome and the diagnoses of depression associated with loss and mourning.

\section{Discussion}

Castilho ${ }^{1}$ teaches us that under the complaint of memory problems are grouped distinct events that can get to locate its specificity, through the input of analytical listening. To do so, is to produce an interval in the rapid correspondence between episodes of forgetfulness and pathologies. The elderly are often faced with significant losses, which can happen in a successive way: losses of loved ones, loss of ideals, confrontation with the fragility of the body, loss of the relationship with work due to retirement, among others. Mucida ${ }^{2}$ tell us that these losses from aging require mourning work, since many rearrangements that the subject has made collapse, and with them, many of the ideals. Castilho $^{1}$ also reminds us that the complaint of feeling lonely and isolated is frequent in some elderly people, which indicate a certain emptying in the relationships, which may contribute to a progressive isolation, a recurrent issue in the clinic with the elderly. Beyond these difficult questions, there is yet another complicating factor: in times when information circulates at the speed of light, immediacy is required, also for the elaboration of the death of the companion of a lifetime, for example. According to the fifth edition of the Diagnostic and Statistical Manual of Mental Disorders, published by the American Psychiatric Association, within two weeks after the loss, a drug protocol is authorized. Space is then opened for the diagnosis of major depressive disorder, if the state of mourning does not subside after this short period. This demand is of the order of the impossible, inasmuch as it takes time and elaboration for the work of mourning to take place. This DSM-V prescription of conduct goes in the opposite direction to that advocated by Freud ${ }^{3}$ in Luto e Melancolia, when the author tells us that mourning is not a pathological condition, even if it causes a certain departure from the normal conduct of life. It also emphasizes that it considers inappropriate the indication of medical treatment and emphasizes that it takes time for the mourning to be elaborated. Mucida ${ }^{2}$ points out that unprocessed mourning can lead to depressive states. Thus, the modifications and losses arising from old age demand treatment.

\section{Conclusion}

As Castilho \& Bastos ${ }^{4}$ affirm, the innumerable losses of significant ties in the context of old age confront the subject with the solitude proper to the precariousness of the human condition, with the feeling of strangeness. Mucida ${ }^{2}$ tells us that it is an additional difficulty when the elderly appear under the effect of the remedies. However, as Castilho ${ }^{1}$ reminds us, it must be considered that, in some situations, medication enables the elderly to leave the house and go to an analyst, and we must analyze at each time the function of the medication for the subject. The purpose of psychoanalytic listening, in these cases, is to invite the patient to talk about what has been called depression, in order for the subject to resort to history and produce associations. In such cases, it was not uncommon for this input from analytical work to open up to mourning. In this same direction, Castilho ${ }^{1}$ points out that the analyzes with the elderly are, at first, strongly marked by an environment of mourning. In this way, our intention is that psychoanalysis can contribute strongly in the processes of elaboration and construction under analysis.

\section{Acknowledgements}

The authors are grateful to all the members of the Postgraduate Program of Clinical Institutional Psychology of University of the State of Rio de Janeiro for their continued support. The authors would especially like to thank Glória Castilho for your immense contribution.

\section{Conflict of interest}

Author declares that there is no conflict of interest. 


\section{References}

1. Castilho G. Acerca de uma queixa de 'problemas de memória' na velhice: Signorelli e Acrópole. Rio de Janeiro: Escola Letra Freudiana, 2015.

2. Mucida A. O sujeito não envelhece: psicanálise e velhice. Belo Horizonte: Autêntica. 2006.
3. Freud S. Luto e melancolia. In: Edição Standard Brasileira das Obras Psicológicas Completas de Sigmund Freud. XII. São Paulo: Companhia das Letras, 2010.

4. Castilho G, Bastos A. Sobre a velhice e lutos difíceis: "eu não faço falta". Psicol. rev. (Belo Horizonte). 2015;21(1):1-14. 